DESIDOC Journal of Library \& Information Technology, Vol. 33, No. 3, May 2013, pp. 243-252

(C) 2013, DESIDOC

\title{
Journal of Informetrics: A Bibliometric Profile
}

\author{
Prabir Kumar Das \\ Library, Documentation \& Information Science Division \\ Indian Statistical Institute, 203 B.T. Road, Kolkata-700 108 \\ E-mail: prabirdas2003@yahoo.com
}

\begin{abstract}
This paper critically analyses 239 scholarly communications published in the inaugural five volumes of Journal of Informetrics ( $\mathrm{JOI}$ ) to examine growth of literature, types of communications, authorship pattern, collaboration trend, predominant research domains, etc. Subsequent analysis focuses on prolific contributors, degree of collaboration, and time-lag trend. Findings reveal that - publication output doubles over the study period as article publications increase considerably; though single-authored contributions were significant ( $30 \%$ ), majority of contributions were collaborated by two-authors (36 \%), while average authorship accounts for 2.28 per communications. Degree of collaboration (DC) was impressive (0.699) but not overwhelming as research collaborations has emanated from 199 higher learning institutions of 32 countries across the globe. Ranking of prolific contributors has shown Prof. Egghe on the top followed by L Bornmann; R Rousseau and L Leydesdoff. Result also shows upward trend of keyword usage with an average of 4.55 per items, of which $h$-index, citation analysis, bibliometrics, $g$-index, etc, expectedly predominates. Scholarly nature of source journal has been further ascertained from increasing citations and reference usage trend. Moreover, growing hardness of the field has been attributed to $\mathrm{JOI}$ due to the increasing usage of tables and figures. Study also showed that the journal takes an average of about four month time to publish a manuscript.
\end{abstract}

Keywords: Bibliometrics, bibliometric analysis, LIS journals, informetrics

\section{INTRODUCTION}

Informetrics is an active and specialised subdomain of information science formally introduced by Prof. Otto Nacke, in 1979, but the concept became popularised since the first International Informetrics Conference (1987). The rationale behind the introduction of a new discipline mainly arises from the inability of the existing disciplines like bibliometrics and scientometrics to subsume fairly comprehensive aspects of the mathematical view on problems in the area of information science ${ }^{1}$. However, generally 'informetrics' encompasses the study of quantitative aspects of information in any form including records, bibliographies, social groups and scientists. Tague-Sutcliffe ${ }^{2}$ broadened the scope of informetrics by adding two phenomena:

(a) Definition and measurement of information; and

(b) Types and characteristics of retrieval performance measures to the earlier concept.

Thus, it could accommodate and utilise many studies on information measurement that hitherto lied outside the purview of bibliometrics and scientometrics. Then, Egghe $^{3}$ more comprehensively suggested "Informetrics is the generic-term encompassing all-metrics studies related to information science, including bibliometrics (bibliographies, libraries, ...), scientometrics (science policy, citation analysis, research evaluation, ...), webometrics (metrics of the web, the internet or other social networks such as citation or collaboration networks), ...". So, informetrics is the study of quantitative aspects of information which includes production, dissemination, retrieval, and measurement of information, regardless of its form or origin. However, Bar-llan ${ }^{4}$ in her review has shown evolution of 'informetrics' as an emerging sub-domain of information science. Afterwards, Mayr \& Umstätter ${ }^{5}$ quantitatively justified the need for a new journal in the field of informetrics.

\section{GENESIS OF THE SOURCE JOURNAL}

Need for dedicated quality publication outlet for informetric literature was first perceived by Prof. Leo Egghe in 1989 and again during his guest editorship of two special issues (on informetrics) of Elsevier's Information Processing \& Management journal. One main reason was the steady growth in the field of informetrics as new topics have been emerging every now and then, consequently innovative metric tools, indicators, and indices are being proposed by informetricians to gauge current research. Existing 
journals like Scientometrics, JASIST have somehow cope with the situations either by increasing number of issues per year (both of these journals increased frequencies from 2005 and 1998 respectively) or have forced to expand the scope of the existing publication (in case of Information Processing and Management). One feasible alternative might be to publish special issues to showcase the contemporary trends, these are only but temporary measure. The viable solution to report the current research of any fast growing fields (viz., informetrics) is to broaden the reach by creating dedicated specialist journals, which have proven enormous successful earlier. All these have made it reality to emerge Journal of Informetrics (JOI).

The $\mathrm{JOI}$ is a scholarly peer-reviewed journal that publishes communications on fundamental quantitative aspects of information science which are likely improve the 'degree-of-hardness' in the field of informetrics and consequently increase the 'exactness' of the scientific specialty. It was launched by Elsevier Science, UK, on 12 January 2007. In the inaugural editorial, Prof. Egghe (Chief-editor) has categorically mentioned the scope of journal is to publish quality refereed articles on fundamental quantitative aspects of information science with good exposition of mathematical treatment. It also focuses on the communications dealing with rudimental theories, models and techniques of mathematics, statistics and operations research which could facilitate logical explanation of certain phenomena, and procedure of information management in libraries and information centres. In pursuance of above philosophy, JOI provides a unique channel for exchanging innovative ideas and developments in inter and multi-disciplinary areas like bibliometrics, scientometrics, webometrics, cybermetrics including quantitative linguistics. Primary goal is to identify analogues problems in those fields, and devise general theorem, methodology, and procedure which would be all pervasive.

In the very second year of inception, the $\mathrm{JOI}$ became the winner of prestigious Association of Learned and Professional Society Publishers (ALPSP) award for the best new journal. Since then it has been included in ISI (Thomson Reuter) and subsequently received first impact factor during 2009 . Soon the journal has been included in the UN's information delivery initiatives like HINARI (www.who.int/hinari), AGORA (www.aginternetwork), and OARE (www. oaresciences.org) to facilitate free and low cost access to the world's journal literature in developing countries across the globe. Leading secondary services like Current Abstracts, CSA Database, Current Contents, EBSCOhost, LISA, PubMed, SCOPUS, SSCI, TOC Premier, and WoS cover this journal and helps to maintain impressive average impact factor (3.586). The JOI being the flagship journal of 'informetrics' literature thus a potential candidate for an in-depth study in anticipation to further supplement some more interesting findings to the existing literature. Details of the journal are available at www.elsevier.com/locate/joi.

\section{LITERATURE REVIEW}

Bibliometric studies of scholarly LIS journals are well documented and diversified, it was found that half of the total literatures of information science are on bibliometric studies and majority of those were on information use studies generally in the forms of surveys and citations analysis ${ }^{6}$. However, author considered it relevant to mention only those, which are significant in some way or the other. Earliest survey on single journal bibliometric studies was conducted by Tiew ${ }^{7}$ and found 40 studies (out of 102) belongs to individual journal's characteristic studies. Young ${ }^{8}$ reported a study based on Library Quarterly $(L Q)$ to identify total publications; rank list of authors; most frequently cited $L Q$ authors and article in WoS. Again, Verma ${ }^{9}$, et al. analysed 131 contributions of Annals of Library \& Information Studies during 1999-2005 to examine year-wise, institutions-wise, state-wise distribution of contributions, authorship pattern, citation analysis, length of the contributions etc. Singh ${ }^{10}$, et al. had studied the growth and characteristics of digital library literature based on more than 1000 articles retrieved from LISA plus appearing during 1998 to 2004 . Bakri \& Willett ${ }^{11}$ updated the earlier work of Tiew ${ }^{12}$, et al. to identify significant changes of the scholarly behaviours of the journal. Park ${ }^{13}$ examined authorship characteristics of top 20 LIS journals from the Asian and Pacific region based on the WoS data during 1967 to 2005. Mukerjee ${ }^{14}$ revisited JASIST to show growth of papers, authorship patterns, nature of collaboration, geographical dispersion, nature of cited and citing references, prolific authors and highly cited authors, etc. Halder \& Chandra ${ }^{15}$ highlighted growth, authorship pattern, subject trends, distribution of references, illustrations and state wise distribution of contributors of articles appeared of IASLIC Bulletin during 2003 to 2007. In a review, Zainab ${ }^{16}$, et al. reported 11 bibliometric studies on LIS journals'. Recently, Thanuskodi ${ }^{17}$ studied Library Philosophy and Practice for 2005-2009 to report that majority of articles were single-authored and 'computer applications in the LIS' was the predominant area of research. Various authorship elements, viz., most productive author, their affiliation and geographical distributions, etc., of $D$-Lib Magazine was investigated by Park ${ }^{18}$. Again, Journal of Documentation was revisited by Tsay \& Shu ${ }^{19}$ to explore various bibliometric characteristics. From study on Electronic Library journal, Hussen ${ }^{20}$, et al. showed that majority of the articles were singleauthored as the degree of collaboration is very low 
(0.256); majority of authors were librarians, faculty or researchers affiliated with institutions of higher learning. Thanuskodi ${ }^{21}$ studied Library Herald journal to report that majority of contribution was singled authored; journal articles were predominant channel of communication, which received maximum citations. Singh $^{22}$, et al. summarised the publication trends, authorship pattern and geographical dispersions of the contributors of the DESIDOC Bulletin of Information Technology. In the same year, Kumar \& Moorthy ${ }^{23}$ studied DJLIT for 2001-2010 to explore growth and authorship pattern, content coverage and subject distribution. Recently, Egghe ${ }^{24}$ has reported a brief profile with decent overview of $\mathrm{JOI}$ through short communication but a detail analysis of this esteem journal is still due. Hence a sincere effort has been pursued to study the Journal of Informetrics (JOI) quantitatively aiming in view to explore its scholarly profile, like many predecessors.

\section{SCOPE AND OBJECTIVES}

Present study is confined to the publications appeared in the inaugural five volumes of Journal of Informetrics during 2007 to 2011 . The study is conducted based on the research communications like articles, editorial notes, short communications and letter to editors, etc. Noteworthy is the fact that so-called less scholarly communications like - short communications; editorial notes; letters to the editor; etc., were unlikely taken into consideration for the study because of rich intellectual contents. But, communications like - conference announcements, list of reviewers, etc., were excluded from the purview of this study. However, present study is conducted towards the following specific objectives:

- To investigate the chronological growth of informetrics literature;

- To study authorship pattern of the published literatures;

- To enumerate ranking of prolific contributors and their affiliated institutions;

- To determine the extent of research collaboration among the contributors and their affiliated institutions and countries;

- To ascertain the scholarly nature of the source journal from the study of various bibliometric like - keyword, tables and charts usage; references appended, citation received, etc;

- To deduce the time lag for publishing and identify the average time lags for this scholarly journal; and

- To ear-mark various issues quantitatively to rationale the significance of this source journal in the field of informetrics.

\section{METHODOLOGY}

Keeping in view of the aforesaid objectives, primary data for the study has been extracted from the Science Direct database of Elsevier Science. Which facilitate full-text access to the journal site and offers excellent content with powerful search functionality and timely updates. Methodology employed in the present study is basically bibliometric scrutiny, which is used for data collection and analysis of relevant bibliometric attributes of the communications published in the $\mathrm{JOI}$. Complete searching has yielded 239 unique records that are considered reasonable sample for the purpose of this study. Relevant bibliographic elements of specific communications, viz., year and type of publication, contributor/s name, number, affiliations, collaboration types, keywords supplied, number of tables/charts included, number of references appended, number of citations received (by particular item), date of receiving the and date of acceptance of the individual manuscript, etc., are recorded in MS Excel spread sheet and subsequently analysed for making insightful observations and interpretations.

Relevant bibliometric techniques were applied to analyse the retrieved dataset objectively so as to gauge the bibliometric pattern of the JOI. Rank lists of prolific contributors and their affiliated institutions have been prepared based on the fractional counting method $^{25}$ and normal counting method respectively. Research collaboration among the scholars has been estimated in terms degree of collaboration (DC) using Subramanyan's formula ${ }^{26}$. Different bibliometric elements of $\mathrm{JOI}$, viz citation and reference frequency, keyword distributions and table and graph distribution of the journal have been tabulated. Thus a thorough analysis of collected data has been worked out in different dimensions using various mathematical and statistical techniques.

\section{ANALYSIS AND FINDINGS}

Analysis of collected data has revealed many interesting findings which signify many scholarly attributes of the source journal.

\subsection{Year-wise Distribution of Contributions}

Table 1 shows chronological distribution of types of items published in the journal during the study period. Total 239 communications was appeared during 2007 to 2011, of which 212 (88.70\%) were scholarly articles and rest of 27 communications belonged to short communications (5.02\%), letter to editors $(5.02 \%)$, and editorials in negligible portion $(1.24 \%)$. So, research articles were found to be the most predominant form of research communications in $\mathrm{JOI}$. It is also evident that, research communications became double during five years period. Table also shows an increasing trend of total communications 
DJLIT, VOL. 33, NO. 3, MAY 2013

Table 1. Year-wise distribution of types of items published in JOI

\begin{tabular}{llllllll}
\hline & \multicolumn{7}{c}{ Year of publication } \\
Items & $\mathbf{2 0 0 7}$ & $\mathbf{2 0 0 8}$ & $\mathbf{2 0 0 9}$ & $\mathbf{2 0 1 0}$ & $\mathbf{2 0 1 1}$ & Total & Percentage \\
\hline Articles & 32 & 32 & 31 & 62 & 55 & 212 & 88.7 \\
Short Communication & - & 2 & 2 & 2 & 6 & 12 & 5.02 \\
Editorials & 1 & - & 1 & 1 & - & 3 & 1.25 \\
Letter to Editor & - & - & 2 & 4 & 6 & 12 & 5.02 \\
Total & $\mathbf{3 3}$ & $\mathbf{3 4}$ & $\mathbf{3 6}$ & $\mathbf{6 9}$ & $\mathbf{6 7}$ & $\mathbf{2 3 9}$ & $\mathbf{1 0 0}$ \\
\hline
\end{tabular}

with corresponding increase of research articles - signifies that growth of total publications in $\mathrm{JOI}$ followed almost similar trend to that of articles publications over the same period.

\subsection{Authorship Pattern}

Authorship is the important bibliometric measures reflecting contemporary communication patterns, productivity and collaboration among the researchers. Thus, knowledge of authorship could be helpful in assessing research patterns at individual, organisational, and also in disciplinary levels. For authorship study, name and corresponding affiliations of individual contributor were collected from Science Direct as primary dataset. In case of contributors having more than one affiliation in the same articles, only the first affiliation was considered. Various facets of authorship, viz., authorship patterns, i.e., categorisation of authors according to authorship values, average authorship per contribution, collaborative research carried out by the community, determination of the degree of collaboration (DC) among the contributors, identification of prolific contributors in the subject specialty are deduced using this dataset.

Table 2 represents the authorship pattern identified in the $\mathrm{JO} /$ communications during 2007-2011. Analysis shows a total of 545 occurrences of authors in different authorship positions during the period, thus average authorship was found 2.28 for each publication. It was also observed that though singleauthored contributions were quite significant (30\%), two-authored contributions (36\%) were found to be most predominant, followed by three authors (19\%), four authors $(3 \%)$ and rest of the communications were in collaborations ranging from five to even nine-authors. Noteworthy is the fact that reported average authorship for the journal Scientometrics ${ }^{27}$ was almost identical (2.29) to the JOI.

\subsection{Ranking of Prolific Authors}

Table 3 enumerates the ranking of contributing authors based on their weighted value of total contributions in $\mathrm{JO} /$ during the study period. Weighted value of contributors have been calculated using fractional counting method; where total weight (one) of an article is distributed equally among all the (co-authors for multi-authored) contributions irrespective of their position. This could produce more distinctive listing of authors and subsequently removes anonymous ranking ${ }^{28}$.

Results show a total of 326 unique authors have 545 occurrences in different authorship positions of 239 contributions of $\mathrm{JOI}$ during the study period. It is also observed that top 10 positions (ranks) were occupied by ten eminent bibliometricians. Editor-in-chief, Leo Egghe (Universiteit Hasselt, Belgium) was found to be the most prolific author followed by Lutz Bornmann (ETH Zurich, Switzerland); Ronald Rousseau (KHBO, K U Leuven, Belguim); Loet Leydesdorff (University of Amsterdam, The Netherland); Hans-Dieter Daniel (ETH Zurich, Switzerland); Marek Kosmulski (Lublin University of Technology, Poland); Wolfgang Glänzel (K.U. Leuven, Belgium), etc. It is also found from the list that majority of the productive contributors are senior academician of informetrics and allied fields and associated with active institutions of informetric research. Many of them have served as editorial members of the JOI. Similar incidents also reported by Young ${ }^{8}$ and Tiew $^{12}$, et al. in their respective

Table 2. Distribution of JOI communications by authorship

\begin{tabular}{lllllllll}
\hline Year & $\begin{array}{l}\text { Total } \\
\text { communications }\end{array}$ & Solo & Two & Three & Four & $\mathbf{>}$ & Total & Average authors \\
\hline 2007 & 33 & 13 & 9 & 5 & 4 & 2 & 72 & 2.18 \\
2008 & 34 & 14 & 13 & 4 & 3 & - & 64 & 1.88 \\
2009 & 36 & 10 & 13 & 5 & 4 & 4 & 91 & 2.52 \\
2010 & 69 & 22 & 29 & 10 & 5 & 3 & 145 & 2.1 \\
2011 & 67 & 13 & 22 & 22 & 7 & 3 & 173 & 2.58 \\
Total & $\mathbf{2 3 9}$ & $\mathbf{7 2}$ & $\mathbf{8 6}$ & $\mathbf{4 6}$ & $\mathbf{2 3}$ & $\mathbf{1 2}$ & $\mathbf{5 4 5}$ & $\mathbf{2 . 2 8}$ \\
Percentage & & $\mathbf{3 0 \%}$ & $\mathbf{3 6 \%}$ & $\mathbf{1 9} \%$ & $\mathbf{3} \%$ & $\mathbf{1 2 \%}$ & $\mathbf{1 0 0 \%}$ \\
\hline
\end{tabular}


Table 3. List of top 10 authors (based on weighted value of contributions)

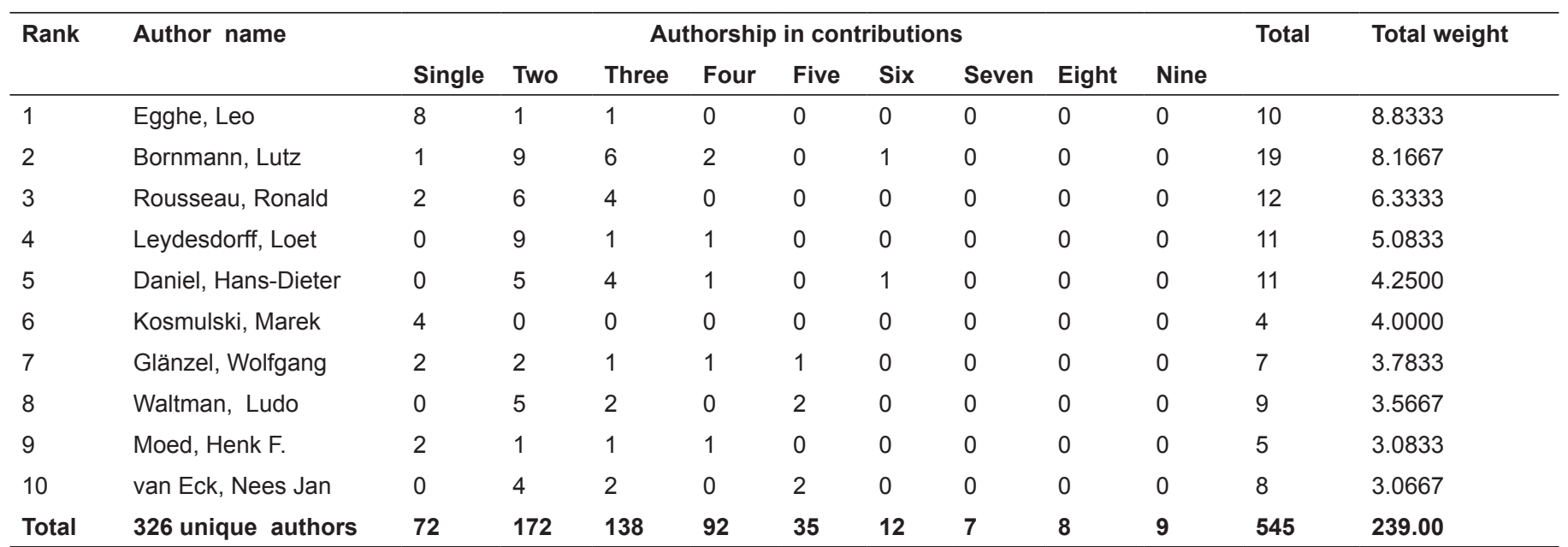

studies. This observation is clearly in concurrence with the declared objective of the journal.

\subsection{Research Collaboration}

Collaboration is an intense form of interaction fostering effective communication as well as sharing of competence and other resources in search of new knowledge. Research collaboration is very much common and highly practiced especially in multidisciplinary domains. Literature shows that research collaboration is discipline dependent and generally higher in the experimental fields of science and technology but lower in the fields of humanities. Here, degree of collaboration (DC) - a proxy measure for research collaboration among the contributors was derived by using Subramanyam ${ }^{26}$ formula, as the ratio of the number of collaborative contributions to the total number of research contributors published in the discipline during a certain period of time. Mathematically it can be expressed as,

$$
D C=\frac{N_{m}}{N_{m}+N_{S}} \quad \text { or }, \quad(D C)_{J O I}=\frac{167}{167+72}=0.699
$$

Where, $N_{m}$ refers to the collaborative communications and $N_{s}$ denote the number of single-authored communications published in a particular communication channel during certain period of time.

Table 4 reveals the collaboration scenario of the contributors of $\mathrm{JOI}$ during 2007-2011. Out of total 239 communications, about $70 \%$ were collaborated by multiple-authors ranging from two to nine co-authors and rests were non-collaborative. Table also shows the degree of collaboration of $\mathrm{JO} /$ varied inconsistently from 0.588 to 0.806 during the study period. Average degree of collaboration was impressive $(0.699)$ but not overwhelming. Gradual increase ( $8 \%$ to $23 \%$ ) of multi-authored communications over the years of $\mathrm{JOI}$ clearly indicates prevalence of team or group research amongst the informetrics community. Similar observation has also found in different fields of basic and applied sciences.

\subsection{Geographical Diffusion of Contributors}

Table 5 shows the geographical diffusion of contributing authors of $\mathrm{JOI}$ during the study period. Country names of the contributors have been identified from the corresponding affiliations as found in respective publications of the journal. Tabulated data shows that contributors from 32 countries of 6 regions (continents) across the globe were associated in producing 239 communications of $\mathrm{JOI}$. Out of which European countries contribute most, followed by North America, and Asia. A rank list of contributing countries has been prepared on the basis of affiliations of the contributions from various countries, applying normal counting method. USA produces highest portion of authors (13\%) by affiliating 69 occurrences, followed by Spain $(11.38 \%)$, The Netherland $(11 \%)$, China (10.9\%), Belgium (8.62\%), UK (6.42\%), etc. It has

Table 4. Collaboration trend (Degree of Collaboration (DC)) among the contributors

\begin{tabular}{llllll}
\hline Year & Non-collaborative $\left(N_{s}\right)$ & Percentage & Collaborative $\left(N_{m}\right)$ & Percentage & DC \\
\hline 2007 & 13 & 5.44 & 20 & 8.37 & 0.606 \\
2008 & 14 & 5.86 & 20 & 8.37 & 0.588 \\
2009 & 10 & 4.18 & 26 & 10.88 & 0.722 \\
2010 & 22 & 9.21 & 47 & 19.67 & 0.681 \\
2011 & 13 & 5.44 & 54 & 22.58 & 0.806 \\
Total & $\mathbf{7 2}$ & $\mathbf{3 0 . 1 3}$ & $\mathbf{1 6 7}$ & $\mathbf{6 9 . 8 7}$ & $\mathbf{0 . 6 9 9}$ \\
\hline
\end{tabular}


DJLIT, VOL. 33, NO. 3, MAY 2013

Table 5. Geographical diversity of contributing authors of the $\mathrm{JOI}$

\begin{tabular}{llllll}
\hline Rank & Country name & Regions & Frequency of author & Percentage & $\begin{array}{l}\text { Cumulative } \\
\text { percentage (\%) }\end{array}$ \\
\hline 1 & USA & North America & 69 & 12.66 & 12.66 \\
2 & Spain & Europe & 62 & 11.38 & 24.04 \\
3 & The Netherland & Europe & 60 & 11.01 & 35.05 \\
4 & China ( with PRC) & Asia & 55 & 10.09 & 45.14 \\
5 & Belgium & Europe & 47 & 8.62 & 53.73 \\
6 & UK & Europe & 35 & 6.42 & 60.18 \\
7 & Switzerland & Europe & 32 & 5.87 & 66.05 \\
8 & Canada & North America & 26 & 4.77 & 70.83 \\
9 & Italy & Europe & 25 & 4.59 & 75.41 \\
10 & Germany & Europe & 22 & 4.04 & 79.45 \\
& Another 22 countries & & 112 & 20.05 & 100 \\
Total & 32 countries & & 545 & 100 & 100 \\
\hline
\end{tabular}

also found that top five countries were producing about $54 \%$ of the total authors, indicating a high concentration of informetrics researchers.

\subsection{Institutional Affiliation of Contributors}

Table 6 depicts the distribution of affiliations of the $\mathrm{JOI}$ contributors among various institutions across globe. Enumerated data shows that 545 contributors $\mathrm{JOI}$ were affiliated to 199 institutions from 32 countries. A rank list of affiliated institutions of the contributors has been prepared based on the aggregated value of the contributions from respective institutions. It is observed from the Table that Swiss Federal Institute of Technology (ETH) - Switzerland has

Table 6. Institutions affiliations of the JOI contributors

\begin{tabular}{|c|c|c|c|c|c|}
\hline Rank & Institute Name - Country & Type & Frequency & Percentage & Total $(\%)$ \\
\hline 1 & Swiss Federal Institute of Technology, (ETH) - Switzerland & UNIV & 32 & 5.87 & 5.87 \\
\hline 2 & Leiden University, CWTS - The Netherlands & UNIV & 29 & 5.32 & 5.32 \\
\hline 4 & University of Amsterdam - The Netherland & UNIV & 13 & 2.39 & 2.39 \\
\hline 5 & KHBO (Catholic College Bruges-Ostend) (K.U.Leuven) - Belgium & UNIV & 11 & 2.02 & 2.02 \\
\hline \multirow{2}{*}{7} & Universiteit Hasselt (UHasselt) - Belgium & UNIV & & & \\
\hline & University of Granada - Spain & UNIV & & & \\
\hline \multirow[t]{2}{*}{8} & Politecnico di Torino (Polytechnic of Turin ) - Italy & UNIV & 8 & 1.47 & 4.41 \\
\hline & University of Quebec (Université du Québec à Montréa) - Canada & UNIV & & & \\
\hline 9 & University of Rome - Italy & UNIV & & & \\
\hline \multirow[t]{8}{*}{10} & Dalian University of Technology, WISE Lab - China & UNIV & 6 & 1.10 & 8.80 \\
\hline & Loughborough University - UK & UNIV & & & \\
\hline & Lublin University of Technology - Poland & UNIV & & & \\
\hline & National Taiwan Universit - Taiwan (ROC) & UNIV & & & \\
\hline & SCImago Research Group (SRG ) - Spain & $\mathrm{RG}$ & & & \\
\hline & Royal School of Library and Information Science - Denmark & UNIV & & & \\
\hline & Universidad Carlos III - Spain & UNIV & & & \\
\hline & University of Wisconsin-Milwaukee - USA & UNIV & & & \\
\hline
\end{tabular}


appeared on the top; followed by Leiden University, CWTS - The Netherlands; Institute of Scientific \& Technical Information of China (ISTIC) - China; University of Amsterdam - The Netherland; KHBO (Catholic College Bruges-Ostend) (K.U. Leuven) - Belgium. It is also evident from the table that top 10 institutions have contributed about (43\%) of the total contributions during the study period. Results also showed that majority of contributors were affiliated to the universities and research institutes of developed countries. Active participation of institutions across geographical boundaries implies the recognition and reputation this journal among world informetrics community. Noteworthy is the fact that, majority of the affiliated institutions found in the study was also in the list of similar study made on the journal Scientometrics ${ }^{27}$.

\subsection{Composition of Editorial Board}

Since inception, $\mathrm{JOI}$ has been endowed with an eminent panel of informetricians of international repute to monitor editorial works. Inaugural editorial board consists of as many as 33 eminent scholastics of 17 different countries across the globe, which included USA (11), Belgium (3), The Netrherlands (3), UK (2), Sweden (2). Many of them (including Prof. Egghe) have contributed good number of papers having mathematical treatment on the policy implications for research evaluations in the fields of information science. So, the journal has got tremendous support and acceptance from the world academia.

\subsection{Variations of Bibliometric Elements}

Table 7 shows year-wise distribution of various bibliometric elements of $\mathrm{JOI}$, that are discussed in details in the subsequent paragraphs.

\subsubsection{Distributions of Keywords}

Scholarly journals invariably append number of keywords to reflect the thought content of the research pursued. Keywords are often regarded as the best indicator of scope and subject coverage of research addressed, naturally most of the indexing services incorporate these words. Present study reveals that a total of 1088 keywords were appended with 239 communications of $\mathrm{JOI}$. Third column of Table 7 shows an upward trend of keyword usage with the average of 4.55 keywords per item over the years. Table 8 is the truncated enumeration of keywords with their frequency of occurrences in the records analysed. It reflects total of 690 unique keywords. Most frequently used keyword found in the study is ' $h$-index' (40 times) followed by 'citation analysis '(23 times), 'Bibliometrics' (22 times) and ' $g$-index' (18 times) whereas some 562 keywords were used once. Review of the enumerated keyword revealed that topics related to informetrics allied sub-domains were predominately appeared in this scholarly communications which seems to be in agreement with Prof. Egghe's intention that the journal $(\mathrm{JO} /$ ) would grow in the line with the mutual growth of informetrics and related areas.

Table 8. Frequency distribution of keywords appended in $\mathrm{JOI}$

\begin{tabular}{llll}
\hline Keyword & Frequency & Percentage & Cumulative (\%) \\
\hline -index & 40 & 3.68 & 3.68 \\
Citation analysis & 22 & 2.00 & 5.68 \\
Bibliometrics & 21 & 1.93 & 7.61 \\
g-index & 19 & 1.75 & 9.36 \\
Citation /s & 16 & 1.47 & 10.83 \\
Hirsch index & 14 & 1.29 & 12.11 \\
Impact factor & 10 & 0.92 & 13.03 \\
Peer review & 10 & 0.92 & 13.95 \\
Ranking & 10 & 0.92 & 14.87 \\
Research & 10 & 0.92 & 15.79 \\
evaluation & & 84.21 & 100 \\
Another 680 & & 100 & 100 \\
Total = 690 & 1088 & & \\
\hline
\end{tabular}

\subsubsection{Distributions of Tables and Figures}

Scientific communications have been often characterised by the use of tables and graphs to supplement the summarise data. Moreover, scientific credibility of scholarly communications frequently perceived with the increasing demonstration of tables and graphs, as researchers use graphs and tables to convince their peers about the clarity of findings. Fourth Column of Table 7 shows that 239

Table 7. Year-wise distribution of various bibliometric elements of JOI

\begin{tabular}{|c|c|c|c|c|c|c|}
\hline Year (Vol) & $\begin{array}{l}\text { Total } \\
\text { communications }\end{array}$ & Keywords used & $\begin{array}{l}\text { Tables and } \\
\text { figures }\end{array}$ & $\begin{array}{l}\text { References } \\
\text { appended }\end{array}$ & Citations received & Impact factor \\
\hline 2007 (V1) & 33 & 142 & 229 & 750 & 595 & NA \\
\hline 2008 (V2) & 34 & 160 & 221 & 1523 & 335 & 2.513 \\
\hline 2009 (V3) & 36 & 180 & 257 & 1459 & 313 & 3.379 \\
\hline 2010 (V4) & 69 & 298 & 506 & 2119 & 188 & 3.119 \\
\hline 2011 (V5) & 67 & 308 & 544 & 2173 & 27 & 4.229 \\
\hline Total & 239 & 1088 & 1757 & 8024 & 1458 & \\
\hline Average/item & & 4.55 & 7.35 & 34 & 6.10 & 3.944 \\
\hline
\end{tabular}


communications of the $\mathrm{JOI}$ have appended a total of 1757 tables and figures with an average of 7.35 per item. Results also showed increasing trend of appending tables and figures, indicating increase of 'hardness' of the research communications as suggested by Smith ${ }^{29}$, et al., 'harder' the discipline uses greater number of graphs and figures. So, the result here seems to comply with the basic objectives of the $\mathrm{JOI}$ that the journal $(\mathrm{JOI})$ aims to contribute to increase the 'degree of hardness' of the field of informetrics.

\subsubsection{Variations of Reference Appended}

Table 7 (Fifth Column) shows the year-wise variations of total references appended with the individual communications of the $\mathrm{JOI}$. It reflects that 8024 references were included with $239 \mathrm{JOI}$ communications during the study period. Therefore, on an average about 34 references were appended in each item which varied from 23 to 45 during the study period. Highest number of reference (622) used by the review article of Bar llan (2008), followed by Zhan, Thijs \& Glanzel article (111) in 2011. Out of total 239 communications only one item (Guest editorial of Rousseau \& Wolfram in vol. 2) does not contain any references. Results also revealed that total number of references in the journal has been increasing over time, which suggests the journal is becoming more scholarly.

\subsubsection{Citations Received}

Table 7 (Sixth Column) shows year-wise variations of total citations received by communications of the JOI based on Scopus. Results shows that 239 published communications of the $\mathrm{JO}$ / had received a total of 1458 citations from various literatures up to 20th February 2012. So, published communications of the $\mathrm{JOI}$ received an average of 6.10 citations per item which likely to increase in course of time as suggested by Moed \& Leeuwen ${ }^{30}$. Naturally, relatively older communications have received higher citations as total citations decreased gradually over the years. Highest citation received by an article (68) was identified by the Schubert \& Glänzel (2007) article whereas as many as 98 articles have not received a single citation. Majority of these (89) are in their early stage of citations and published during 2010(35) to 2011(54).

\subsubsection{Time-lag in Publications}

Scholarly journals are often criticised for lengthy time lag in publishing the manuscripts, as lower time-lag is always encouraging for the researchers to pursue their research communications. Communications with lengthy time-gap often failed to produce impact actually intended by the researchers. Here, time lag refers to the time spent between the date of official acceptance of a manuscript and its actual publication in the journal. Here, time lag of all individual articles of $\mathrm{JOI}$ have been counted separately in days and grouped them into various time-slots. Subsequently, the number of articles (frequency) belong to each group is tabulated and statistical mean value of time lag has been calculated, as shown in the Table 9. Result shows an average of about three month has been consumed by the journal to publish the accepted manuscript. Table also shows that, time lag of majority (181) of articles was varying from 3 to 6 months and there is hardly any consistency what so ever. However, implementation of web-based manuscript submission system through Elsevier Editorial System (ESS) would be a great help to ensure timely publication of the accepted manuscripts.

Table 9. Time-lag frequency distribution

\begin{tabular}{ll}
\hline Time lag (Duration) & Frequency \\
\hline Up to 1 month (30 days) & 7 \\
Up to 2 months (from 31 to 60 days) & 14 \\
Up to 3 months (from 61 to 90 days) & 43 \\
Up to 4 months (from 91 to 120 days) & 64 \\
Up to 5 months (from 121 to 150 days) & 36 \\
Up to 6 months (from 151 to 180 days) & 38 \\
Up to 7 months (from 181 to 210 days) & 13 \\
Up to 8 months (from 211 to 240 days) & 5 \\
More than 8 months (>240 days) & 4 \\
Total & $\mathbf{2 2 4}$ \\
\hline (\# Only research articles and short communications are considered)
\end{tabular}

\section{CONCLUSIONS}

Analysis presented in this study has permitted some inferences of broad generality on the bibliometric profiles of the $\mathrm{JOI}$ which illuminates scholarly nature and impact of the journal to the larger community. It also portrays the state-of-the-art of informetrics field and depicts the cognitive structure of the discipline as well.

However, steady increase in number of contributions and maintenance of exceptionally high 'impact factor' over the years, signifies persistence growth of literature with substantial exposure. Moreover, diversity of authorship across the disciplines and countries gives international flavor to the source journal. As desired by Prof. Egghe, many of the editorial board members have contributed good number of papers to the journal. An increasing trend of collaboration among the researchers has been observed in this scientific specialty. Furthermore, Informetrics being trans-disciplinary domain objectively accommodate expositions not only from immediate field but also from broader disciplines - thus produces substantial multi-authored $(70 \%)$ communications as reflected from the study as well. The degree of collaboration (DC) was estimated to 0.699 , of which double and triple-authored contributions were significant. 
Contributors from higher learning Institutions of European Union country clearly predominates in the informetric research. Diversity of contributors and prevalence of collaborative contributions from Europe, America $(\mathrm{N})$ and Asian regions indicates - intellectual perception from various origin have been intermingled into this scholarly communications. Furthermore, being the flagship journal, $\mathrm{JOI}$ has maintained careful balance among the frontier research areas and often publishes landmark studies on informetrics and allied sub-domains. Little surprisingly, topics like $h$-index, citations analysis, bibliometrics, $g$-index, impact factor, and peer review have dominated in the research communications. JOI seems to be credited with high citations as average citations per item accounts to 6.10 within a limited period, which likely to be increasing over time. Perceptible increase of reference usage indicates the journal is becoming more scholarly. Subjective 'hardness' of the journal is ascertained from increasing usage of tables and figures in the journal communications. Findings also reflect that $\mathrm{JOI}$ suffers from time-lag of about four months in publishing the manuscripts. The editorial board has already implemented web based manuscript submission $\mathrm{JOI}$ handling system through ESS and Article Based Publishing (from 2012) to ensure better production coordination so as to avoid delays in publishing what so ever.

In summary, it may be concluded that the journal has achieved most of its objectives in terms of authoritativeness (rigorous reviewing with dynamic editorial procedure), visibility (coverage in leading I\&A services), acceptance (growing citations, high average impact factor) scholarliness (double blind review, in-depth focus of research, timeliness of publication, etc.) and internationality (authorship, editorship, and reviewer). Expectedly, many of these resembles with Egghe's observation ${ }^{24}$. There are, of course, still many unexplored areas for further studies particularly in sustainability and quality assessments like-(Web) citation mapping, web-log analysis, tracking of collaboration-network, etc.

\section{REFERENCES}

1. Nacke, O. Informetrie: Ein neuer Name für eine neue Disziplin. Nachrichten für Dokumen, 1979, 30(6), 219-26.

2. Tague-Sutcliffe, J. An introduction to informetrics, Inf. Proc. \& Manag., 1992, 28(1), 1-3.

3. Egghe, L. Expansion in the field of informetrics: Origin and consequence, Inf. Proc. \& Manag., 2005, 41(6), 1311-16.

4. Bar-llan, J. Informetrics at the beginning of the 21st century: A review. Journal of Informetrics, 2008, 2(1), 1-52.

5. Mayr, P. \& Umstätter, W. Why a new Journal of informetrics needed? Int. J. Sciento. Inf. \& Bib., 2007, 11(1).
6. White, H.D. \& Mccain, W. Bibliometrics In Annual Review of Information Science and Technology, edited by M.E. Williams. American Society for Information Science (Elsevier Science, Amsterdam), 1989, 24, 119-86.

7. Tiew, W.S. Single journal bibliometric studies: A review. Mala. J. Lib. \& Inf. Sci. 1997, 2(2), 93-114.

8. Young, A.P. Library Quarterly 1956-2004: An exploratory bibliometric analysis. Library Quarterly, 2006, 76(1) 10-18.

9. Verma, N.; Tamrakar, R. \& Sharma, P. Analysis of contributions in Annals of Library and Information Studies. Ann. Lib. Inf. Stu., 2007, 54(2) 106-11.

10. Singh, G.; Mittal, R. \& Ahmad, M. A bibliometric study of literature on digital libraries. The Electronic Library. 2007, 25(3), 342-48.

11. Bakri, A. \& Willett, P. The Malaysian Journal of Library and Information Science 2001-2006: A bibliometric study. Mala. J. Lib. \& Inf. Sci., 2008, 13(1), 103-16.

12. Tiew, W.S. Abdullah, A. \& Kaur, K. Malaysian Journal of Library and Information Science 1996-2000: A bibliometrics study. Mala. J. Lib. \& Inf. Sci., 2002, 6(2), 43-56.

13. Park, T. K. Asian and Pacific region authorship characteristics in leading library and information science journals. Serials Review, 2008, 34(4), 243-51.

14. Mukherjee, B. Journal of the American Society for Information Science and Technology (2000-2007): A bibliometric study. IFLA Journal, 2009, 35(4) 341-58.

15. Halder, S.N. \& Chandra, S.A. Bibliometric study of published literature in Library and Information Science in IASLIC Bulletin: 2003-2007. Pearl: A Journal of Lib. \& Inf. Sci., 2009, 3(2), 4-12.

16. Ani, K.W.U.; Zainab, A. N. \& Anur, N.B. Bibliometric studies on single journals: A review. Mala. J. Lib. \& Inf. Sci., 2009, 14(1), 17-55.

17. Thanuskodi, S. Bibliometric analysis of the journal Library Philosophy and Practice from 2005-2009. Lib. Phil. \& Prac., 2010. (available online)

18. Park, T.K. $D$-Lib Magazine: Its first 13 years, $D$-Lib Magazine, 2010, 16(2). (available online)

19. Tsay, M. \& Shu, Z. Journal bibliometric analysis: A case study on the Journal of Documentation. Journal of Documentation, 2011, 67(5), 806-22.

20. Hussain, A., et al. Bibliometric analysis of the 'Electronic Library' journal (2000-2010), Webology, 2011, 8(1). (http://www.webology.org/2011/v8n1/ a87.html/).

21. Thanuskodi, S. Library Herald Journal: A bibliometric study. J. Art. Sci. \& Comm., 2011, 2(4) 68-76. 
22. Singh, K. P., et al. DESIDOC Bulletin of Information Technology: A bibliometric study. SRELS J. Inf. Manag., 2011, 48(1) 57-68.

23. Kumar, M. \& Moorthy, A.L. Bibliometric analysis of DESIDOC Journal of Library and Information Technology during 2001-2010. DESIDOC J. Lib. \& Inf. Technol., 2011, 31(3) 203-08.

24. Egghe, L. Five years "Journal of Informetrics". Journal of Informetrics, 2012, 6(3), 422-26.

25. Van-Hooydonk, G. Fractional counting of multiauthored publications: consequences for the impact of authors. J. Amer. Soc. Inf. Sci \& Tech., 1997, 48(10), 944-45.

26. Subramanyam, K. Bibliometric studies of research in collaboration: A review. J. Inf. Sci., 1983, 6(1) 33-38.

27. Chen Y.; Fang S. \& Börner K., Mapping the developments of Scientometrics: 2002-2008. J. Lib. Sci. China. (available online)

28. Egghe L.; Rousseau R. \& Van-Hooydonk G. Methods for accrediting publications to authors or countries:
Consequences for evaluation studies. J. Amer. Soc. Inf. Sci. \& Tech., 2000, 52(2), 145-57.

29. Smith, L.D., et al. Constructing knowledge: The role of graphs and tables in hard and soft psychology. American Psychologist, 2002, 57, 749-61.

30. Moed, H.F. \& Leeuwen, T.N.V. Improving the accuracy of Institute of Scientific Information's journal impact factors. J. Amer. Soc. Inf. Sci. \& Tech., 1995, 46(6), 461-67.

\section{About the Author}

Mr P.K. Das BSc $(H)$, BLib, MLib is currently serving the profession (for more than 12 years) as Library and Information Assistant at the Library, Documentation \& Information Science Division, Indian Statistical Institute, Kolkata and his research interests includes: Bibliometric and scientometrics, research collaboration, scientific productivity, journal evaluation and literaturebased informetric studies, library consortia, library automation, etc. He has published many papers in the national and international journals. 